\title{
Los cauces de la modernización de los regadíos históricos: el caudal emotivo como apoyo para unir el pasado con el futuro. Estudio del caso del Valle de Lecrín (Granada)
}

\author{
José Ramón Guzmán Álvarez \\ ramonguzmanalvarez@gmail.com
}

\begin{abstract}
Resumen. El regadío en la montaña mediterránea es algo más que infraestructura y campos cultivados. Son cauces artificiales que conducen el agua domesticada hasta los pagos de regadío, fecundando a su paso algunos de nuestros paisajes más queridos. Pero son sistemas que se adaptan mal al paso del tiempo porque, entre otras razones, tienen su fundamento en unas estructuras sociales y económicas definitivamente agotadas. En paralelo a esta crisis, el reconocimiento de las funciones paisajísticas de los sistemas de regadío históricos ha incorporado a nuevos actores que intervienen, de una manera propositiva o activa en la definición del futuro de estas acequias. Estas visiones chocan frecuentemente con el obligado pragmatismo de los agricultores que las usan y que velan porque cumplan la finalidad para las que primariamente fueron concebidas. Por otra parte, y cada vez con mayor frecuencia, la desarticulación de las comunidades rurales, como consecuencia del envejecimiento de la población y la emigración, ha quebrado la base social que permitía el funcionamiento del regadío tradicional. Los agricultores que quedan necesitan adaptar el sistema de regadío, no solo por razones de oportunidad económica, sino porque su mantenimiento bajo los cánones tradicionales ya no es posible. ¿Qué futuro les espera a las acequias tradicionales? En los últimos años se han puesto en práctica distintas soluciones que van desde su conversión a sistemas hidráulicos entubados, hasta su integración en las actuaciones de conservación del medio natural y el paisaje. Partiendo del estudio del caso de los sistemas de regadío del Valle de Lecrín (Granada) se subraya la necesidad de llegar a puntos de encuentro y a soluciones compartidas que reconozcan el carácter evolutivo de estos sistemas, pero que, al mismo tiempo, sean respetuosas con sus valores históricos, patrimoniales o ambientales. En este contexto, el concepto de caudal emotivo puede ser incorporado como criterio para el diseño de las actuaciones de modernización en los regadíos que tengan carácter histórico, cultural o paisajístico.
\end{abstract}

Palabras clave: Modernización, paisaje, patrimonio, transformación de regadíos

\begin{abstract}
Updating bistorical irrigation systems: the "emotive flow" as a concept to support the link between the past and the future. A case study in the Lecrin Valley (Granada, Andalucia, south of Spain). The functions of irrigation in the Mediterranean basin are far beyond agriculture. They are artificial channels driving tame water, gardening some of our most lovely landscapes. Unfortunately they are in some way old-fashioned systems, difficult to update to modern needs, mostly because they are linked to almost vanished social structures Meanwhile, other actors interested in the ecological, cultural and landscape functions of these irrigation systems have appeared, identifying new requirements to take into account when defining the future of these network of channels. These new approaches collide oftenly with the more pragmatic and utilitarian vision from the peasants, who demand technical solutions to modernise their irrigation systems in order to facilitate the work of a decreasing number of water users. When thinking on the future of historic irrigation system, the need of shared solutions between peasants and other actors should be recognised. To support this approach, the concept of "emotive flow" is suggested to be included as criteria in the design of modernisation projects of irrigation systems with historical, cultural and enviromental values, taking the example of the Lecrin Valley (Granada, south of Spain) as a case of study.
\end{abstract}

Keywords: Landscape, history or irrigation, cultural heritage, modernisation

\section{Introducción}

El Valle de Lecrín es una comarca natural situada al suroeste de Sierra Nevada en la provincia de Granada (Andalucía, sur de España). Desde el punto de vista paisajístico destaca su núcleo central, una fosa tectónica a la que vierten diferentes ríos y barrancos tributarios del río Guadalfeo que han excavado cauces en general profundos y angostos. En su conjunto está delimitado en su práctica integridad por un conjunto de relieves montañosos de 
gran personalidad: las estribaciones occidentales de Sierra Nevada, con el cerro del Caballo (3.011 m) como telón de fondo, y las sierras de Albuñuelas y Pinos y las Sierras de los Guájares y de Izbor, prolongaciones de la Sierra de la Almijara. Este conjunto de sierras forman una barrera que ha dificultado el tránsito natural entre Granada y la costa del Mediterráneo. Las sierras del Valle de Lecrín determinan su paisaje pero también, y particularmente, las condiciones de su hábitat al generar un refugio climático y ser el origen de los ríos y fuentes que nacen en las zonas de contacto y que proporcionan el caudal a la red de acequias históricas que recorre sus pueblos: El Padul, Cozvíjar, Cónchar, Dúrcal, Nigüelas, Acequias, Mondújar, Murchas, Melegís, Chite, Talará, Lecrín, Béznar, Ízbor, Pinos del Valle, Saleres, Restábal y Albuñuelas, actualmente agrupados en siete términos municipales (El Padul, Villamena, Dúrcal, Nigüelas, El Valle, Béznar, Lecrín, El Pinar y Albuñuelas).

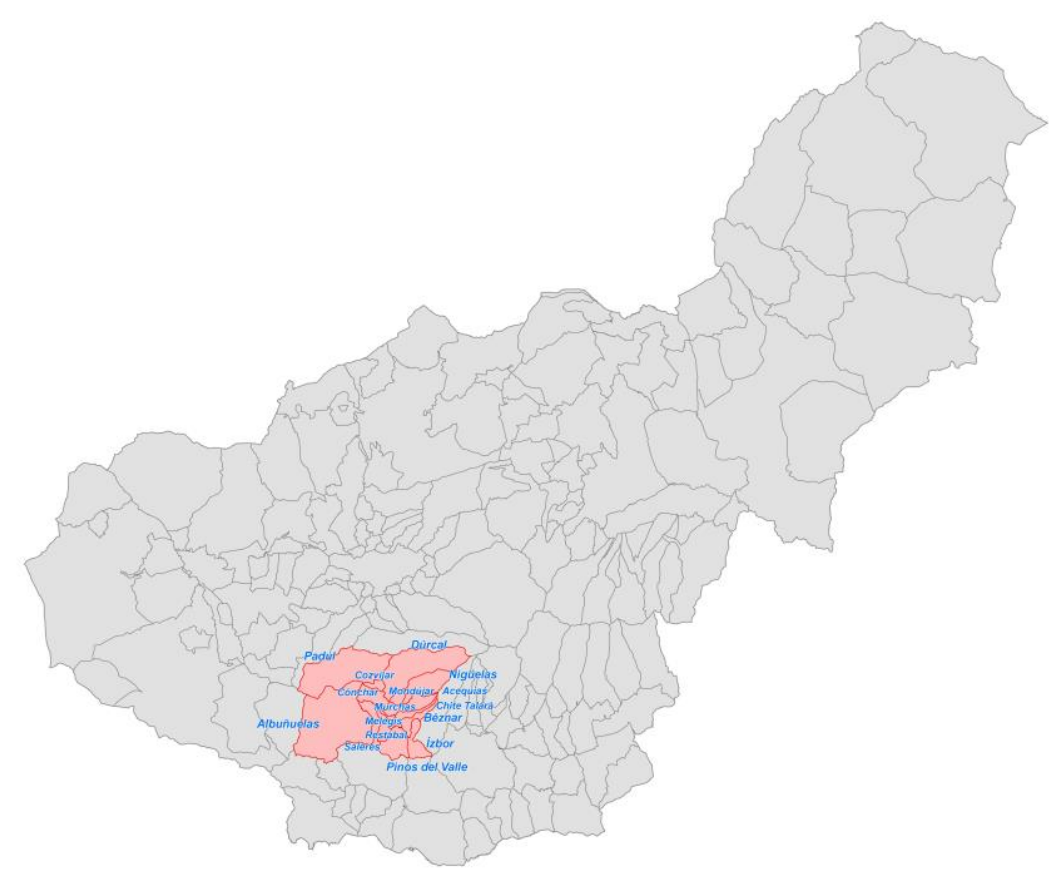

Fig. 1. Localización del Valle de Lecrín en la provincia de Granada.

Contamos con una referencia excelente para conocer el estado de los regadíos del Valle de Lecrín al inicio de la década de 1970: el trabajo de Villegas Molina (1972) sitúa geográficamente la red de acequias del Valle de Lecrín en los años setenta del pasado siglo y, con ello, nos permite el acercamiento a su evolución reciente y estudiar su pasado (Figura 2).

Las acequias del Valle de Lecrín son el resultado de un proceso histórico que ha ido acumulando las modificaciones realizadas por sus habitantes a lo largo de los siglos. Pero en estos pueblos de la provincia de Granada, al igual que ocurre en muchas otras localidades de la Cuenca Mediterránea, la adaptación de los regadíos históricos a los patrones de vida y de explotación de los recursos naturales del siglo XXI está resultando particularmente difícil (Guzmán Álvarez, 2014). 
Tabla 1. Acequias históricas del Valle de Lecrín, adaptado de Villegas Molina (1972)

\begin{tabular}{|c|c|}
\hline Nombre y origen del agua & Pueblos que riega \\
\hline \multicolumn{2}{|l|}{ Río de la Laguna } \\
\hline Acequia Real & Cozvíjar, Cónchar \\
\hline \multicolumn{2}{|l|}{ Río Dúrcal (Sierra Nevada) } \\
\hline Acequia de Márjena & Dúrcal \\
\hline & Dúrcal y El Padul (pago de Marchena), \\
\hline Acequia de Cozvíjar - Marchena & Cozvíjar \\
\hline Acequia de Los Llanos & Dúrcal y El Padul \\
\hline Acequia de Los Arcos & Cónchar, Murchas, Melegís \\
\hline Acequia del Burgo (del Marjen) & Murchas, Melegís, Restábal \\
\hline Acequia de Restábal & Melegís, Restábal \\
\hline \multicolumn{2}{|l|}{ Río Torrente (Sierra Nevada) } \\
\hline Acequia de Nigüelas & Nigüelas, Dúrcal, Mondújar, Acequias \\
\hline Acequia Real de Chite-Talará & Mondújar, Chite, Talará \\
\hline Acequia Alta de Murchas & Murchas \\
\hline Acequia Baja de Murchas & Murchas, Melegís \\
\hline \multicolumn{2}{|l|}{ Río Santo (Sierra de Albuñuelas) } \\
\hline Acequia Alta (de la Alfarería) & Albuñuelas \\
\hline Acequia del Castillo (del molino aceitero) & Albuñuelas \\
\hline Acequia de Restábal & Albuñuelas, Restábal \\
\hline Acequia de Saleres & Albuñuelas, Saleres \\
\hline \multicolumn{2}{|l|}{ Fuentes } \\
\hline Acequia de la Sierra (Fuente Alta) & Mondújar \\
\hline Acequia Alta de Béznar (Baranco de Tablate) & Béznar \\
\hline Acequia del Juncal & Pinos del Valle \\
\hline Acequia de la Zaza y otros & Pinos del Valle \\
\hline Acequia Altera (Barranco del Hundidero) & Ízbor \\
\hline Acequia del Pinar (Barranco del Hundidero) & Ízbor \\
\hline Acequia de la Vega (Barranco del Hundidero) & Ízbor \\
\hline \multicolumn{2}{|l|}{$\begin{array}{l}\text { Acequias del Padul (fuentes del entorno de la la- } \\
\text { guna) }\end{array}$} \\
\hline Acequia de la Fuente del Lino & Cónchar \\
\hline Acequia de la Fuente de los Siete Años & Saleres, Restábal \\
\hline Acequia del Marchal & Saleres \\
\hline Acequia del Moginar (Barranco de Arrendate) & Chite, Talará \\
\hline Acequia del Baño (Nacimiento de la Barraza) & Chite, Talará \\
\hline
\end{tabular}




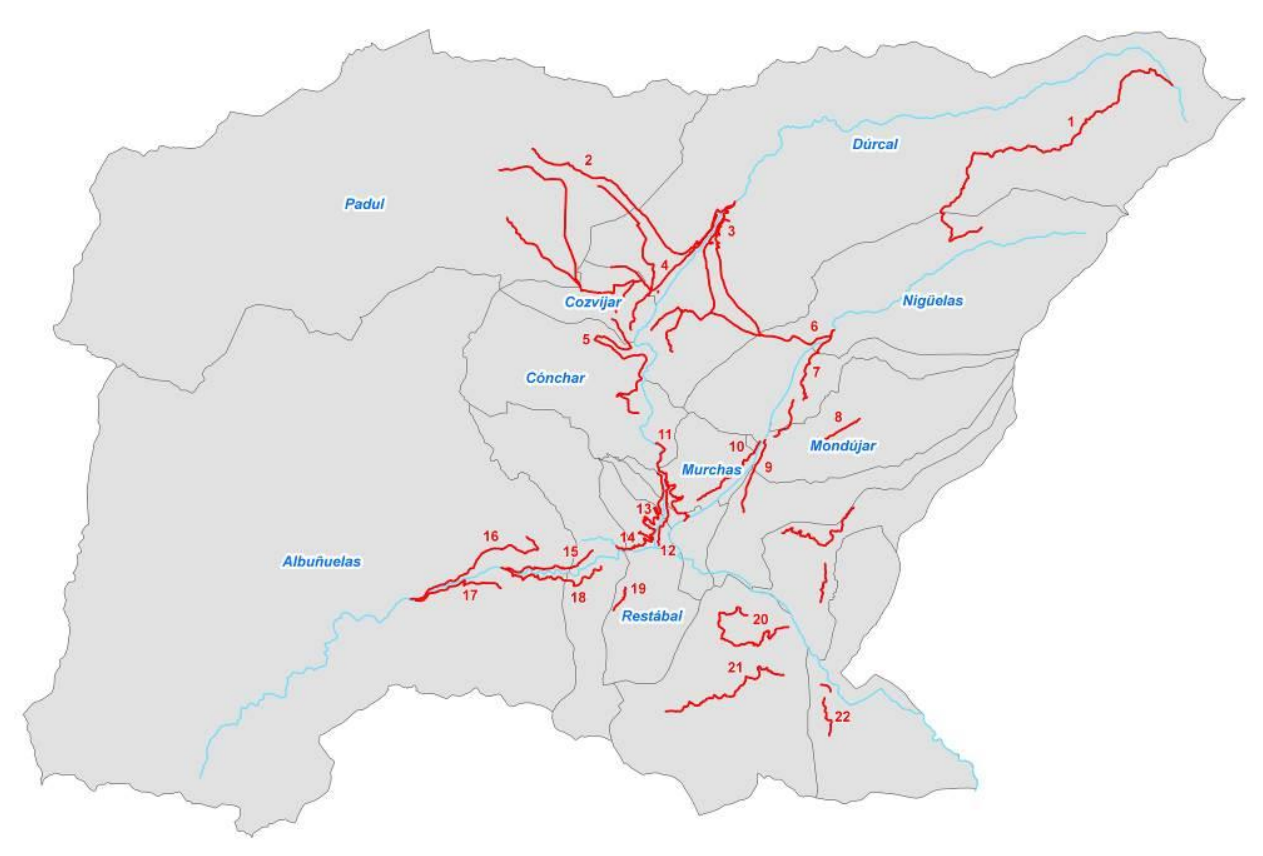

Fig. 2. Principales acequias históricas del Valle de Lecrín (conducciones principales; a partir de Villegas Molina, 1972). 1. Acequia de los Hechos/La Alfaguara. 2. Acequia de Los Llanos. 3. Acequia de Márgena. 4. Acequia de Cozvíjar-Marchena. 5. Acequia de Cónchar. 6. Acequia de Nigüelas-Dúrcal. 7. Acequia de Acequias-Mondújar. 8. Acequia de la sierra de Mondújar. 9. Acequia de Talará-Chite. 10. Acequia alta de Murchas. 11. Acequia de los Arcos. 12. Acequia del Marjen-El Burgo. 13 (14). Acequia de Restábal. 15. Acequia de Saleres. 16. Acequia del Mojinar. 17. Acequia del Castillo. 18. Acequia de Restábal. 19. Acequia de la Fuente de los Siete Años. 20. Acequias de Pinos. 21. Acequia de la Zaza. 22Acequia de Ízbor.

\section{Notas sobre los regadíos históricos del Valle de Lecrín}

Se han conservado registros documentales que nos permiten asignar una historia más que centenaria a la mayor parte de las acequias del Valle de Lecrín. Por los Libros de Habices y los Libros de Apeo y Repartimiento redactados en el periodo comprendido entre la conquista castellana y la expulsión definitiva de la población morisca, tenemos constancia de la presencia en el siglo XVI de un importante número de sistemas hidráulicos, la mayor parte de los cuales corresponden a acequias que aún continúan en uso en la actualidad: varias acequias en el Padul, alimentadas por fuentes, la acequia de Cozvijar-Marchena (Dúrcal y El Padul), la acequia Real de Cónchar, la acequia de Márgina o Márgena (Dúrcal), la acequia de Nigüelas-Dúrcal, la acequia de Acequias-Mondújar, la acequia de los Arcos (Murchas y Melegís), la acequia de el Marje o del Burgo (Murchas, Melegís), la acequia de Restábal que toma del río Dúrcal, las cuatro acequias principales del río Santo de Albuñuelas (del Mojinal o Moxinal, del Castillo, del Lugar, de Restábal y de Saleres), la acequia alta de Murchas, la acequia de Chite - Talará, tres acequias alimentadas por fuentes en Pinos del Rey, entre otras ${ }^{1}$.

1 Se han consultado como fuentes documentales originales los Libros de habices de 1501 (A.G.S., C.M.C., leg. 131) y el Libro de Repartimiento de Cozvíjar (1592), el Libro de Apeo (1572) y de Repartimiento (hacia 1590) de Dúrcal y el Libro de Repartimiento de Cónchar (1593) conservados en el Ar-chivo Histó- 
De estas fuentes se infiere la presencia de acequias de regadío en la tierra de cultivo de la Sierra Nevada de Dúrcal y Nigüelas, a una altitud comprendida entre 1.500 y 2.100 metros. Aunque las fuentes anteriores a la conquista castellana son escasas y no tienen la claridad de los libros de Apeo y Repartimiento elaborados entre 1572 y los primeros años del siglo XVII, es probable que esta red de acequias de montaña estuviera en funcionamiento, al menos, durante el periodo nazarí.

Entre los siglos XVII y XVIII se amplió la superficie de regadío. Se constata en los términos de El Padul y Dúrcal al realizarse la acequia de los Llanos que riega pagos situados en cotas superiores a los que dominaba la acequia previa de Marchena (García Pérez, 2011), y también en otros pueblos en donde aparecen brazales de acequias que riegan pagos declarados como secano en los documentos de finales del siglo XVI.

Posiblemente la actuación hídrica más trascendente llevada a cabo en el Valle de Lecrín con anterioridad al siglo XX fue la desecación de la laguna del Padul, que podemos situar en los años posteriores a 1779, tras la solicitud realizada en este sentido por el Conde de Villamena al Ayuntamiento de Granada (Villegas, 1972). Los trabajos de desecación ampliaron la red de drenaje original del río de la Laguna y modificaron los sistemas hidráulicos preexistentes, desaguando el vaso de una laguna cuya superficie en aquellas fechas los informantes del Catastro de Ensenada estimaban en 3.550 marjales (aproximadamente $185,24 \mathrm{ha})$.

A partir de esa fecha no nos consta la construcción de nuevos sistemas de regadíos de entidad alimentados con agua superficial. De hecho, cuando a mediados del siglo XX se puso en riego el pago Picón, que por su configuración geográfica no era dominado por la acequia histórica de Márgena, se recurrió a la captación a partir de un sondeo.

Durante el siglo XX se hicieron modificaciones importantes en los sistemas hidráulicos. Las captaciones sobre el río Torrente, que con anterioridad a la década de 1950 se realizaban principalmente a través de presas (aunque también debería contarse con el apoyo de galerías subálveas), fueron mermando, de manera que los regantes se vieron obligados a ampliar la longitud de las galerías. Tal fue el caso de la acequia alta de Murchas como conocemos por la aprobación el 29 de julio de 1967 del "Proyecto modificado del de mejora y ampliación de la captación de aguas subálveas' en el barranco Torrente para la mejora y ampliación de los regadíos" (BOE nº 211/1967).

La acequia de Nigüelas, situada aguas arriba de la cuenca del río Torrente, mantuvo sus características originales. Aunque su caudal puede reducirse en los años especialmente secos, presenta muchas más garantías que el resto de sistemas hidráulicos del río Torrente. Ello se debe, obviamente, a su posición en relación con las otras redes de acequias, pero también a otra circunstancia que le aporta gran singularidad. Además de aprovechar el agua que fluye por la cuenca del río Torrente, este sistema hidráulico se nutre de aportaciones del deshielo que de manera natural recorrerían la cuenca del vecino río Dúrcal, pero que son canalizadas a través de la acequia de los Hechos o de la Alfaguara, una acequia de montaña que recorre el cerro del Caballo desde las proximidades de su cima (2.800 me-

rico Provincial de Granada (Signaturas 6677 y 6678 para Dúrcal, 6692 para Cónchar y 6693 para Cozvijar) que han sido transcritos para este trabajo. Para los Libros de habices posteriores se ha consultado la edición de Padilla Mellado, 2010. Asimismo se han revisado las ediciones de los Libros de Apeo y Repartimiento de Nigüelas (Ferrer, 2000), Albuñuelas (Ferrer, 2005), El Padul (Ferrer, 1994) y Melegís y Restábal (Espinar et al, 2006), Pinos del Rey e Ízbor (García Pérez, 2013). 
tros) hasta una cota de en torno a los 2.000 metros, en donde el agua se derrama a un barranco que conduce el agua al río Torrente propiamente dicho. El resultado final es una transferencia de agua entre dos cuencas que debió ser fruto de un acuerdo histórico entre los regantes de los términos afectados. La mención en el Libro de Repartimiento de Dúrcal (1603) de una acequia de la dehesa y de una acequia vieja induce a pensar que esta acequia de montaña, que actualmente incluimos en el conjunto de las acequias de careo de Sierra Nevada (Cano-Manuel y Ortiz, 2010), fue construida con anterioridad al siglo XV. Este sistema hidráulico enlazado (acequia de Nigüelas / acequia de los Hechos) fue objeto de modificación a raíz de la puesta en funcionamiento en 1996 de la central hidroeléctrica de Nigüelas, prolongándose el recorrido de la acequia de los Hechos para que el agua alcanzase una mayor cota. También sufrió otra modificación sustancial que aún no tenemos datada: la integración con el sistema hidráulico de Acequias-Mondújar, que discurre por la otra orilla del río Torrente, y que en el siglo XVI debía contar con una presa de derivación propia, mientras que en la actualidad toma el agua de la misma presa que la acequia de $\mathrm{Ni}$ güelas-Dúrcal, repartiéndose el caudal en un partidor inicial que distribuye una parte para los pagos de Nigüelas, otra parte para los de Nigüelas y una tercera parte para la acequia de Acequias-Mondújar que ha de cruzar el lecho del río.

El aprovechamiento hidroeléctrico también originó un canal que toma el agua en la cabecera del río Dúrcal, a unos 1.680 metros, en la Sierra de este término, para abastecer a la central hidroeléctrica de Dúrcal construida a principios del siglo XX. También se construyó por esa época una central hidroeléctrica en Cozvijar - abandonada en los años sesenta que aprovechaba el caudal del río de la Laguna y la del vecino río del Alcázar, para lo cual se construyó una mina que atraviesa la loma que separa ambos cauces.

Cada pueblo tenía uno o varios molinos harineros y de aceite accionados por el agua. Molinos que derivaban el agua del cauce de los ríos, pero que, más frecuentemente, eran movidos por el agua de las acequias, como todavía es posible contemplar en Acequias o Nigüelas.

La irregularidad climática mediterránea da lugar en la comarca a años de lluvias y a años secos. Las fuentes y manantiales responden a estos pulsos que tienden a cierta periodicidad, como reconocieron los paisanos que bautizaron con el nombre de fuente de los Siete Años a uno de los manantiales que aportaban agua a los regadíos históricos de las tierras altas de Saleres y Restábal. Conocemos, por otro lado, las variaciones que ha experimentado el clima mediterráneo en los últimos siglos, con periodos caracterizados por una pluviometría superior a la media y otros en los que la aridez es más intensa de lo común. Durante los decenios generosos en agua, los manantiales rompen con abundancia y regularidad, permitiendo la puesta en explotación de nuevos sistemas hidráulicos o la recuperación de antiguas redes de acequias en desuso. En el periodo actual, caracterizado por su mayor aridez relativa, es posible identificar estos sistemas hidráulicos fosilizados a partir de las huellas que la antigua red de acequias ha dejado en el parcelario o en los planos topográficos y en las fuentes documentales antiguas. En el Valle de Lecrín existen ejemplos muy interesantes en el término municipal de Villamena a lo largo del valle del río Alcázar, en el pago del Llano del Alcázar, en el barranco de la Cañada del Moral, en la rambla de Cijancos o en Fuente Bordana. Las fuentes documentales, la toponimia y el estudio del territorio permiten hacer también una reconstrucción de la paleohidrología del Valle, localizando fuentes y manantiales perdidos o lagunas desaparecidas, como las que se ubicaban junto al camino viejo de Granada a Albuñuelas en el término de Saleres, al sur del caserío de Nigüelas o sobre el pueblo de Béznar. 
Las fuentes históricas nos hablan de paisajes mucho más fecundos en agua que los actuales. Con la presencia de ríos en lugares en donde hoy en día encontramos barrancos y ramblas de cauce espasmódico, cuyos manantiales sólo rompen los años singularmente lluviosos. Fuentes que aportaban suficiente caudal como para dar lugar a pagos de tierras de riego en lugares que hoy nos sorprenden. Y una relativa abundancia de sistemas de regadío basados en el esquema fuente (usualmente asociada a una excavación en mina) / alberca de almacenamiento que aprovechaban los acuíferos del barranco de las Cuevas en Albuñuelas, en el Marchal en Saleres o en el valle del río Alcázar en Cónchar.

Y en la sierra, unos aprovechamientos de agua singulares. Al sur, en la meseta de Albuñuelas (situada en la prolongación oriental de la sierra de Almijara), los repobladores cristianos se encontraron con cierto número de cortijos que deberían satisfacer sus necesidades de agua a partir de pozos, como pone de manifiesto la referencia a algunos de ellos en el Libro de Repartimiento de Suertes de Albuñuelas: el pozo del Sauz, el pozo del Madroñal, el pozo del Ladrón... Al norte, los pueblos colindantes con la Sierra Nevada - El Padul, Dúrcal, Nigüelas, Acequias, Mondújar, Béznar - incluían entre su terrazgo pagos ubicados en los materiales metamórficos de Sierra Nevada, más allá de los farallones de arenas, dolomías y calizas de los ásperos relieves alpujárrides. Tierras que fueron puestas en cultivo en una época indeterminada y que aún conservan los nombres por los que fueron conocidas por los repobladores (La Malla, el Posteruelo, el barranco del Yesar, la raya de la Dehesa...).

\section{La evolución reciente de los regadíos del Valle de Lecrín}

El paisaje del Valle de Lecrín ha cambiado profundamente en los últimos decenios. Y ello a pesar de que muchos rasgos de la estructura del terrazgo no han sufrido apenas variación como la enorme parcelación, heredera de tiempos pasado: valga como ejemplo que, de acuerdo con el Libro de Apeo de Dúrcal, las posesiones que Alonso de Cazalla (que podía ser considerado el terrateniente del Valle de Lecrín) tenía a censo de los habices de la iglesia de Dúrcal en 1572 sumaban 213 marjales de riego (11,11 ha) repartidos en 114 hazas.

Han cambiado los usos y costumbres, las técnicas de cultivo, los equipos utilizados por la labranza... Los cultivos herbáceos de regadío han desaparecido prácticamente de gran parte del territorio; los bancales se han poblado de arboleda. En las localidades del valle inferior (Chite, Murchas, Restábal, Melegís, Saleres, Pinos del Valle, Béznar...), de clima más suave, se extendieron los cítricos, sobre todo a partir de los años sesenta; más tarde, en la década de los noventa, fueron acompañados, de forma más tímida, por nísperos y aguacates. Los olivos centenarios de la orilla de las terrazas fueron respetados dando lugar a un paisaje singular y atractivo. En el valle alto, en las vegas de Nigüelas, Dúrcal, Cózvíjar o Cónchar se implantaron frutales o se aumentó el número de olivos, tendencia que se ha agudizado en los últimos años.

En los últimos años han cambiado muchas cosas. La red de acequias estudiada por Villegas Molina continúa pero algunas de ellas han experimentado cambios profundos, algunos de ellos resultantes de la acumulación de pequeñas intervenciones, otros provocados por actuaciones de gran entidad.

El diseño y puesta en funcionamiento del embalse de Béznar, construida entre 1977 y 1986, tuvo importantes efectos directos e indirectos. Anegó una porción considerable de la vega de los pueblos del centro de la depresión; pero también significó un revulsivo para 
la agricultura de la comarca al incluir como medida compensatoria la utilización de 4,3 $\mathrm{hm}^{3}$ /año para la mejora de 823 ha de regadíos del Valle de Lecrín. Esto se concretó en la construcción de una nueva red de canalizaciones que permite derivar agua del río de la Laguna a los regadíos del interior del Valle, reemplazando a las fuentes efímeras que alimentaban las vegas de Murchas, Talará, Melegís, Chite o Béznar.

Las acequias que tomaban agua de la sierra o de fuentes de escaso caudal dejaron de usarse, algunas de ellas se sumieron en el olvido. A veces estas tierras continuaron siendo cultivadas en secano, pero de una manera temporal: la mayor parte de esta superficie ha sido abandonada. Sin embargo, la superficie de regadío ha aumentado en su conjunto debido a la explotación de agua subterránea mediante sondeos.

La modernización de los regadíos en el Valle de Lecrín ha seguido diferentes vías y caminos. A finales de los años setenta los sistemas de regadío que aprovechaban el agua de los manantiales de la sierra de Restábal y Saleres fueron transformados aprovechando los incentivos canalizados por el Instituto de Reforma y Desarrollo Agrario (Real Decreto 1616/1978). La acequia del Mojinal en Albuñuelas fue objeto de una importante intervención, construyéndose un estanque de regulación y adecuando la presa del río. En los últimos años, el apoyo público a la mejora y modernización de regadíos ha tenido como base reguladora los reglamentos comunitarios de desarrollo rural, pero apenas ha sido aprovechado; una excepción es la acequia del pago Picón, en Dúrcal, que, como hemos visto, es un sistema de riego relativamente reciente.

A falta de grandes transformaciones en el conjunto de la red, muchos regantes han optado por soluciones a escala de parcela (pequeños depósitos de regulación) que permiten cambiar el sistema de riego por gravedad, sujeto a turno y tanda, al riego por goteo automatizado.

Las comunidades de regantes han ido haciendo adaptaciones puntuales en su red de acequias, cementando tramos, entubando otros, atendiendo las necesidades perentorias a través de aportaciones extraordinarias de los comuneros o aprovechando fondos de actuación local. En conjunto, las redes de acequias principales mantienen gran parte de sus rasgos pasados. Apenas se han llevado a cabo actuaciones sobre la globalidad de la red, que siempre exigen un mayor esfuerzo económico y, especialmente, de organización. Las comunidades de regantes aparentemente más reacias a la modernización integral parecen coincidir con aquellas que disponen de una mayor garantía de suministro y que carecen del estímulo provocado por la escasez de agua.

La evolución socioeconómica de las últimas décadas también ha actuado en sentido opuesto, aumentando en ocasiones la disponibilidad de agua. El abandono rural, la insuficiencia del parcelario para mantener agricultores en activo, ni siquiera a tiempo parcial, ha dado lugar a que algunos pagos hayan sido prácticamente abandonados. La construcción de nuevas infraestructuras, en particular la autovía Granada-Motril y el crecimiento del casco urbano de los pueblos, ha modificado parcialmente la red de acequias, o ha llevado a la desaparición a una fracción considerable de la superficie regable.

En el entretiempo, las comunidades de regantes han debido ajustar sus normas de funcionamiento para acomodarse a las nuevas circunstancias. La reducción del número de agricultores, el envejecimiento de la población y los cambios en los hábitos de vida han obligado a modificar algunas de las antiguas normas. Con frecuencia, las reglas de funcionamiento de la comunidad de regante se han ajustado a los cambios provocados por 
la transformación de la infraestructura de regadío, como ha ocurrido al entrar en funcionamiento estanques de regulación que evitan los incómodos turnos de riego nocturnos. En la acequia del Castillo de Albuñuelas, por ejemplo, una de las que han sido modernizadas durante estas últimas décadas, los turnos de riego se recuerdan con carteles situados en los principales nudos de la red de conducciones.

En ocasiones, los cambios de en las normas de uso y disfrute del agua han profundizado en una tendencia que ya Villegas Molina detectó: cuando el agua sobra, no es preciso ajustarse demasiado a normas. Sistemas de reparto del agua basados en una cantidad determinada de agua por unidad superficie (medida generalmente en unidades de tiempo, como era usual en los regadíos de las alquerías del Valle de Lecrín en el siglo XVI) dejan de ser necesarios, por lo que el sistema de riego por turnos es reemplazado por el riego a la demanda, pidiendo la vez. Este cambio se constata en Cónchar, en donde una vez que la central hidroeléctrica del río de la Laguna dejó de funcionar, aumentó el caudal de agua disponible para la acequia Real, quedando solamente sujeto a regulación el jueves, día reservado para las parcelas situadas al final del área regable en el pago de la Fuente del Lino. En Marchena y en Cozvijar, por el contrario, la escasez de agua, sobre todo en los años de sequía (que, de acuerdo con la percepción de los regantes, "van a más") ha impulsado a nuevos acuerdos entre los miembros de la Comunidad lo que en el caso de la acequia de Cozvíjar ha supuesto respetar el riego por brazales o sectores, y en el de Marchena de Dúrcal ha dado pie a la contratación de un acequiero que "esté pendiente" del agua y ordene los turnos, tras muchos años sin contar con esta figura.

El relativamente escaso grado de transformación de estos sistemas hidráulicos permite que aún estén activos elementos ligados a la arquitectura del agua de enorme interés: los conjuntos de arcos de la acequia de los Arcos de Murchas, uno de ellos construido con sillares de aparente origen romano apoyados sobre una pared rocosa (si bien no es posible deducir con certeza el origen premedieval de esta conducción, dado que los sillares podrían haber sido reutilizados), y el otro un par de elegantes arcos de medio punto de mampostería que salva el cauce de un barranco; las minas que horadan el potente nivel de conglomerados que debe superar la acequia de Acequias-Mondújar; la doble trinchera de la acequia de Nigüelas-Dúrcal que corta las dolomías de los Foyatones de Nigüelas, una de ellas destinada al paso del agua, la otra a camino de andén; las canaletas sobre pilares de mampostería sobre el barranco del Pleito (Mondújar), en la rambla de Cijancos (Cónchar) o en el río de la Laguna (Cozvíjar). Partidores que probablemente lleven distribuyendo equitativamente el agua desde hace más de cinco siglos, como el que reparte el cauce a partes iguales entre los pagos de Cozvíjar y el pago de Marchena (Dúrcal y el Padul); presas que han debido ser remozadas y reelaboradas en cientos de ocasiones ante la fragilidad de los materiales y la acometida de las crecidas de los ríos Dúrcal, Torrente o Albuñuelas. Acequias olvidadas cuyo trazado es reconstruible por la presencia de taludes de configuración natural imposible, que han debido ser usadas y abandonadas respondiendo a la benignidad o a la dureza de los ciclos de lluvia; incluso acequias colgadas, fosilizadas, que evidencian su antigüedad al haberse quedado por encima del cauce del río Dúrcal, que no ha dejado de profundizar su lecho mientras el tiempo pasaba por los hombres y sus creaciones.

\section{$4 \mathrm{El}$ futuro de las acequias históricas del Valle de Lecrín. El caudal emotivo como criterio de diseño}

La red de acequias del Valle de Lecrín continúa aportando el agua que dota de personalidad a una comarca caracterizada por su agricultura insuficiente. Una comarca que ha ga- 
nado en los últimos años en estima social por sus valores paisajísticos. Un espacio que ha dejado de ser un espacio rural propiamente dicho para estar integrado en el espacio rururbano de la vecina aglomeración de Granada, con unos hábitos de vida de la población local muy alejados de los de sus antepasados.

Una comarca que agrícolamente tiene difícil encaje en el contexto económico actual, caracterizado por una especialización e intensificación creciente. Una agricultura insuficiente desde el punto de vista económico pero que aún modela el territorio, ya sea como actividad secundaria que complementa las rentas procedentes de otras fuentes de ingresos, ya como una actividad ligada al esparcimiento y estrechamente vinculada al cariño a la tierra de aquellos que desean cuidar sus raíces en los pueblos del Valle. Con la aparición de iniciativas pujantes pero de escaso alcance, de agricultura ecológica o de producciones locales comercializadas en canales cortos. Y con una mayoría de labradores envejecidos que no acaban de amoldarse a los ritmos de la modernidad, si es que fuera posible hacerlo.

En este territorio secular, resulta difícil la adaptación de las estructuras de poblamiento y de las infraestructuras rurales, concebidas para dar respuestas a las necesidades del siglo XVI o del XIX. Al igual que las callejas de los pueblos no permiten el tránsito de los coches, el parcelario, la red de acequias, los usos y costumbres para el reparto del agua se adecuan con dificultad a las expectativas y requerimientos de los labradores del siglo XXI.

Pero si no hay adaptación, la alternativa es el abandono. Y la adaptación implica cambio, evolución, transformación. El reto es cómo hacerlo de forma respetuosa con nuestra propia historia. Porque en los últimos años nos hemos percatado, sobre todo desde el mundo urbano (o el psicológicamente urbano que vive en el medio rural) de los valores históricos, culturales, paisajísticos y naturales de estos sistemas de regadío. En un momento en el que nos sorprendemos de que sigan teniendo uso productivo infraestructuras diseñadas y construidas hace siglos.

No obstante, las soluciones que se aportan desde la lejanía emocional, a menudo se desinflan ante la tozuda realidad de aquellos que manejan las acequias y siguen viviendo dentro de su lógica, las siguen manteniendo en su día a día. Y frecuentemente resulta difícil, incluso deshonesto, aplicar dosis de empatía social y tratar de convencer a los regantes de las bondades de sistemas que para ellos son claramente obsoletos y que demuestran que han perdido la batalla de la contemporaneidad en la que todos vivimos. Cuando nos recuerdan con sorna que la mayoría de los que opinamos somos desertores de la azada, que vivimos alejados del ciclo de los trabajos y los días en ecosistemas artificiales.

Y, sin embargo, no deberíamos renunciar a la admiración que nos producen estos sistemas hidráulicos, al reconocimiento a trabajos de ingeniería brillantes diseñados con instrumentales topográficos efectivos, ya fueran plomadas, niveles o corobates, que nos pueden parecer rudimentarios en comparación con nuestros GPS. Y es bueno compartir con humildad esa admiración con los que mantienen vivos los paisajes del agua domesticada: a fin de cuentas, los sistemas hidráulicos sin agua que corra por ellos son objetos para la arqueología, no para alimentar los paisajes del territorio y los paisajes del alma.

¿Podemos llegar a puntos de encuentro? Al menos lo deberíamos intentar (Guzmán Álvarez, 2010) pero necesitamos, ante todo, ejemplos que nos demuestren que son posibles las soluciones compartidas. 
Estos sistemas de regadío, como queda apuntado en esta breve síntesis del caso del Valle de Lecrín, no han dejado de evolucionar, continúan evolucionando. Sería descabellado pensar que se pueden conservar del mismo modo que antaño, que los regantes del siglo XXI hagan lo mismo que sus abuelos. Demos su espacio al tiempo y busquemos soluciones acomodadas al siglo XXI. Posiblemente un buen principio sea asumir el cambio como rasgo intrínseco de los sistemas hidráulicos, pero situando los esfuerzos en moderar los efectos de transiciones excesivamente bruscas evitando, en la medida de lo posible, intervenciones irreversibles, sobre todo sobre aquellos elementos que sean especialmente destacables por su valor patrimonial.

Hay recetas para ello. Parece evidente que si coincidimos en reconocer el valor de los regadíos históricos, no podemos aplicarles los mismos criterios de modernización, de adaptación al siglo XXI, que a los regadíos que no cuentan con tanta historia a sus espaldas. Una aplicación miope de la Directiva de aguas o de los Reglamentos europeos de apoyo al desarrollo rural nos impulsaría a invertir dinero público en el entubamiento de estos sistemas de regadío para alcanzar un objetivo aparentemente loable: el ahorro de agua. Pero no estaríamos entendiendo que estos sistemas nos aportan servicios que se derivan de su aparente ineficiencia: el riego por gravedad alimenta veneros y las filtraciones en las canalizaciones da vida a la vegetación que nos alegra y alberga la biodiversidad que apreciamos.

Lo anterior, sin embargo, tampoco puede llegar a convertirse en un principio absoluto. El agua es un bien cada vez más escaso y preciado, y lo último que desearían los regantes es que sus acequias de distribución se desangren antes de hacer llegar el agua que necesitan sus parcelas. Es una cuestión de sensatez: pueden ser tolerables pequeñas pérdidas en las conducciones principales, en acequias terrizas o de hormigón, pero la intervención es ineludible ante pérdidas que se consideren excesivas.

Los regantes demandan sistemas que les permitan regar con comodidad. De eso depende el mantenimiento de sus cultivos, la obtención de productos que sean objeto de comercialización o de autoconsumo. De otro modo, si anclamos los sistemas hidráulicos al pasado en aras a la protección patrimonial, la consecuencia puede ser el abandono de la actividad agraria y, con ello, la ruina del paisaje que bienintencionadamente se pretende conservar.

El Valle de Lecrín ofrece buenos ejemplos para la reflexión: ¿qué hubiera sido de los olivares centenarios de Saleres y Restábal si no se hubiera transformado el antiguo sistema de riego de la acequia de los Siete Años, si no se hubiera cambiado de fuente de abastecimiento, si no se hubiera instalado riego por goteo automatizado? Es muy probable que hoy en día contemplásemos un territorio abandonado. Hemos aportado comodidad y racionalidad al regadío, pero, en contrapartida, hemos abandonado a su suerte a las acequias históricas que han quedado vacías de contenido. En realidad, se ha producido una ruptura histórica mayor: el regadío ha dejado de estar ajustado a los ciclos hidrológicos anuales, las fuerzas impulsoras del sistema ya no son la gravedad, la evaporación y la precipitación, si no que lo hemos hecho dependiente de la energía fósil, entrando a formar parte de otro tipo de preocupaciones y consideraciones. Pero en esto, no hemos nada más que incorporar el sistema de Restábal a nuestra cotidianeidad, para lo bueno y para lo no tan bueno.

En conclusión: prestar atención y atender de forma particular a los regadíos históricos nos exige formular propuestas que reconozcan su carácter evolutivo y dinámico. Y, especialmente, que sean queridas, interiorizadas por los gestores directos, a no ser que dispongamos de los fondos públicos suficientes y continuos en el tiempo como para llevar a cabo otro tipo de soluciones. 
Este carácter evolutivo permite incorporar nuevas funciones a los regadíos. O prestar atención a algunas que siempre han cumplido los sistemas de regadíos históricos, pero a las que no les hemos prestado la suficiente atención a la hora de formular soluciones técnicas para su modernización: la capacidad de alimentar emociones.

El sonido del agua, especialmente en ambientes secos, nos vivifica. Su contemplación en movimiento reconforta. Al menos es así para la mayoría de nosotros. El lenguaje de la poesía, de la contemplación, es una buena herramienta para comunicar esta función.

$\mathrm{Y}$ al igual que nos preocupa que en los ríos represados el agua corra - al menos una fracción - para finalidades ecológicas: ¿por qué no reconocer que también queremos dejar que corra para que siga cubriendo nuestras necesidades emocionales?

El caudal emotivo puede ser incorporado como criterio para el diseño de actuaciones de modernización en sistemas de regadío históricos. No todas las acequias ni todos sus tramos cumplen del mismo grado esta funcionalidad. Pero en el caso de que reconozcamos que un tramo determinado de acequia es importante para nutrir nuestras emociones, ello nos dará pie a adoptar respuestas técnicas adecuadas. Respetando por ejemplo, tramos sin entubar en redes de riego que aconsejen su transformación. Duplicando tramos de manera que parte del caudal siga corriendo por una acequia descubierta mientras que la otra parte, probablemente el mayor caudal, vaya entubado. Poniendo en valor acequias con gran valor emocional, reforzando los vínculos de los paisanos o los excursionistas ocasionales con el paisaje emotivo.

En el Valle de Lecrín también contamos con ejemplos de reconocimiento de la emotividad como atributo de los sistemas de regadío. Reconocimiento que quizás no se haya hecho de forma explícita, pero que ha permitido tener en cuenta a las emociones al diseñar soluciones técnicas ante retos de modernización de conducciones de regadío. Y aunque también hay ejemplos en el otro sentido, paisajes a los que les hemos quitado el sonido y la visión del agua, merece la pena fijarnos en aquellos otros paisajes que han conservado sus valores emotivos o que los han reforzado, generando escenarios especialmente propicios para el disfrute de los sentidos.

Hay un entorno en particular en donde la intencionalidad es manifiesta, en donde la intervención técnica ha sido especialmente concebida para despertar las emociones que nos suscita el agua domesticada que se aleja presurosa por un paisaje espectacular. El tramo inicial de la acequia de Nigüelas nos reta a desvelar su historia; su camino de andén se ha adaptado para que el paseante ocasional comparta recorrido con el acequiero y los labradores. A veces se camina sobre una rejilla, directamente sobre el agua que fluye; otras, por pasarelas que acrecientan el asombro y la admiración por aquellos que diseñaron y ejecutaron la acequia.

Nigüelas ofrece la oportunidad de reforzar nuestros vínculos con el agua domesticada. Y nos convence de que el agua debe continuar regando sus pagos, sus parcelas minúsculas y su agricultura insuficiente. La acequia de Nigüelas, en definitiva, nos reta a que sigamos manteniéndola, gestionándola, respetándola. 


\section{Agradecimientos}

A Javier Venegas Troncoso por su ayuda en la creación del SIG y en el tratamiento de la información territorial.

A mi padre, Juan Manuel Guzmán García, de quien tanto he aprendido: en estos paisajes ha dejado a buen recaudo su trabajo, su conocimiento, su técnica y su sensibilidad.

\section{Referencias}

Cano-Manuel, J.; Ortiz Moreno, E. (2010): Los cauces fabricados: el paisaje construido para el agua, en, Guzmán Álvarez, J.R. y Navarro Cerrillo, R.M., ed., El agua domesticada: los paisajes de los regadios de montaña en Andalucía, pp. 217-227.

Espinar Moreno, M.; González Martín, C.; de la Higuera Rodríguez, A.; Gómez Noguera, C. (2006): El V alle. Libros de Apeo y Repartimiento de Melegís y Restábal, Ayuntamiento de El Valle, Granada.

Ferrer, M. (1994): Libro y demás instrumentos de la Población del Lugar del Padul del Partido del Valle de Lecrín. Año de 1571, Ayuntamiento del Padul, Granada.

Ferrer, M. (2000): Libro de Apeo y Repartimiento de Suertes de Nigüelas, 1572, Ayuntamiento de Nigüelas.

Ferrer, M. (2005): Libro de Apeo y Repartimiento de Suertes de Albuñuelas, Ayuntamiento de Albuñuelas, Granada

García Pérez, J.F. (2011): Territorio y poblamiento medieval en el Valle de Lecrín. La alquería de Padul, Editorial Alhulia, Granada.

García Pérez, J.F. (2013): Libros de Apeo y Repartimiento de las alquerías de Pinos del Rey, Ysbor y Tablate. Apeos y Repartimientos del año 1572. Círculo Rojo Editorial.

Guzmán Álvarez, J.R. (2010): Un futuro para el agua domesticada en la montaña mediterránea, en, Guzmán Álvarez, J.R. y Navarro Cerrillo, R.M., ed., El agua domesticada: los paisajes de los regadios de montaña en Andalucia, pp. 555-558-

Guzmán Álvarez, J.R. (2014): Los paisajes del agua domesticada en la Alpujarra., en: Titos Martínez, coord., La provincia de Granada y el agua, Fundación Agua Granada, Granada, pp 227- 243.

Padilla Mellado, L. (2010): Los habices de las iglesias del Valle de Lecrin. Historia y Arqueología, Tesis Doctoral,. Universidad de Granada, Granada.

Villegas Molina, F. (1972): El Valle de Lecrín. Estudio Geográfico, Instituto de Geografía Aplicada del Patronato Alonso de Herrera, Granada. 